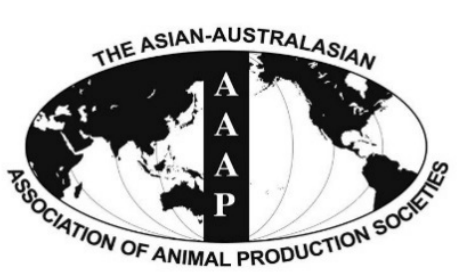

Open Access

Asian Australas. J. Anim. Sci.

Vol. 29, No. 7 : 1060-1064 July 2016

http://dx.doi.org/10.5713/ajas.15.0734

www.ajas.info

pISSN 1011-2367 elSSN 1976-5517

\title{
Behavioral Characteristics of Weaned Piglets Mixed in Different Groups
}

\author{
Hyun-Su Hwang, Jae-Kang Lee, Tae-Kyung Eom, Seung-Hun Son, \\ Joon-Ki Hong ${ }^{1}$, Ki-Hyun Kim ${ }^{1}$, and Shin-Jae Rhim* \\ School of Bioresource and Bioscience, Chung-Ang University, Ansung 456-756, Korea
}

\begin{abstract}
With regard to animal welfare concerns, behavioral information of weaned and mixed piglets is great interest in swine production. The aim of this study was to demonstrate the change in behavior of weaned piglets over time in two different groups (littermates and piglets from different litters) after mixing. Two weaned groups of piglets (72 individuals in all) housed either with littermates or with foreign piglets ( 6 individuals in $1.8 \mathrm{~m} \times 1.4 \mathrm{~m}$ pens, $28^{\circ} \mathrm{C} \pm 1{ }^{\circ} \mathrm{C}$ temperature) were observed with the aid of video technology for 9 consecutive hours on days 1,2, and 3 after mixing. The behaviors of the weaned piglets in the control and treatment groups were significantly different among the days after mixing. Piglets were, however, more active and aggressive in the groups with foreign piglets. This study reveals a lower level of agonistic behavior in groups of piglets that came from the same litter. (Key Words: Agonistic Behavior, Animal Welfare, Littermate, Video Technology)
\end{abstract}

\section{INTRODUCTION}

Several studies have shown that the rearing environment can influence swine behavior (Hillman et al., 2003). However, it is not clear which aspects of behavior, such as space use, substrate use, social inter-relations, are influenced. Mixing is a common practice in modern swine husbandry. In a pasture-farrowing system, piglets were weaned at 6 to 10 weeks of age. When swine production moved to enclosed spaces, weaning age began to decrease. Piglets were usually mixed at weaning and at an early stage of life to better utilize housing facilities (Benson and Rollin, 2004; Li and Wang, 2011). Currently, most piglets being reared under commercial conditions are separated from their mother when they are 3 to 4 weeks of age (Fels et al., 2012).

Sudden changes in diets, neighbors, rearing conditions, and housing brought about by mixing are major stressors for piglets (Varley and Wiseman, 2001). Mixing of

\footnotetext{
* Corresponding Author: Shin-Jae Rhim. Tel: +82-31-670-4842, Fax:+82-31-676-4842, E-mail: sjrhim@cau.ac.kr

${ }^{1}$ Swine Science Division, National Institute of Animal Science, Cheonan 331-801, Korea.

Submitted Sept. 3, 2015; Revised Oct. 15, 2015; Accepted Oct. 22, 2015
}

unfamiliar piglets usually result in behavioral changes. Aggressive behavior, in particular, can increase after mixing (Parratt et al., 2006). Consequently, the resulting social and physiological stress can affect growth rate, cause injury, and in extreme cases, lead to death (Arey and Edwards, 1998). In addition, the rearing environment of a piglet can influence the development of behavior, which in turn can influence the piglet's behavioral response to stressful environments in later stages of life ( $\mathrm{Li}$ and Wang, 2011). Moreover, piglet behavior following mixing is clearly a welfare concern, and this concern has stimulated a search for husbandry methods that will help reduce such stress (Broom, 2011; Rhim, 2012).

Any regrouping of piglets brings about agonistic behaviors for the establishment of a social hierarchy within a group (Fels et al., 2012). The existence of social hierarchy within a group is known to be critical for sustaining a stable social structure. Agonistic behaviors, which include biting, head knocking, threatening, pushing, chasing, and avoidance behavior, have been observed after mixing in many studies (Giersing and Andersson, 1998; Colson et al., 2006). After the establishment of the social hierarchy, fighting among group members declines because of the avoidance strategies practiced by the subdominant individuals towards the dominant individuals (Langbein and 
Puppe, 2004; Rhim et al., 2005).

Socialized pigs establish a new social hierarchy more quickly (D'Eath, 2005). However, there is a lack of information on the relation between a piglet's origin litter and the behavior of individual piglets after mixing. The aim of the present study was to show the change in behavior in weaned piglets over first 3 days in two different groups (littermates and piglets from different litters) after mixing.

\section{MATERIALS AND METHODS}

The experiment was conducted at the experimental farm of the National Institute of Animal Science in Cheonan (Chungnam Province, South Korea) using 72 pigs (Yorkshire $\times$ Landrace). Piglets were farrowed in $1.8 \mathrm{~m} \times 1.4$ $\mathrm{m}$ pens with solid plastic flooring and a heat lamp. Piglets were weaned at $28( \pm 1.5)$ days of age and mixed in different groups: control (6 individuals of littermates) and treatment (6 individuals from foreign piglets) groups in a $1.8 \mathrm{~m} \times 1.4$ $\mathrm{m}$ pen. The average initial body weight of the piglets when placed in a pen was $6.7 \pm 0.2 \mathrm{~kg}$. For treatment groups, piglets were randomly selected from litter.

The environmental control systems were the same among all housing facilities. The temperature in each pen was controlled by ventilation fans and heaters and was maintained at approximately $28^{\circ} \mathrm{C} \pm 1^{\circ} \mathrm{C}$. In this study, temperature may not affected on piglets' behavior caused by lower ambient temperature. Cool environment may derive piglets to huddle and physical contacts. Each pen was provided with a stainless steel feeder and one nipple drinker that allowed for ad libitum access to food and water throughout the experiment. The experimental protocols describing the management and care of animals were reviewed and approved according to the Guide for the Care and Use of Laboratory Animals (National Institute of Animal Science, Animal Care Committee of Korea) in 7 March 2014 (approval number: NIAS 2014-289).

Six replicates were evaluated for the control and treatments groups. One wide-angle video camera was installed at the center of the ceiling, so that all the areas of the pen could be observed. The behaviors of the piglets in the groups were video-recorded continuously for $9 \mathrm{~h}$ per day for 3 consecutive days. All behavioral data were obtained from video images that were digitally recorded from 09:00 to 18:00 $\mathrm{h}$ on days 1, 2, and 3 after weaning and mixing. Instantaneous scan sampling was carried out at 10min intervals. All video recordings were viewed by trained observers who were blinded to the treatments to eliminate subjective bias and interindividual discrepancy ( $\mathrm{Li}$ and Wang, 2011; Rhim, 2012).

The following behaviors were recorded: drinking, feeding, chewing on other animals, inactivity, agonistic behavior, locomotion, pen exploration, belly nosing, excretion, and other behaviors (Table 1). The frequency and duration of these piglet behaviors were recorded by video on days 1,2, and 3 after weaning; the individual performing the behavior, as well as the individual receiving the behavior, was noted. The behavioral time values presented are the means and standard errors of the relative frequencies of each behavior, calculated from the results obtained from each observation of each group (Rhim, 2012; Rhim et al., 2015).

In particular, all agonistic encounters were registered by recording the latency, duration, and frequency of occurrence. Agonistic behavior was defined as follows: encounter between two pigs that involved physical contact (biting, head-thrusting, ramming, or pushing with the opponents standing in antiparallel position and with both performing bites or knocking), and started with the first physical contact and ended with submissive behavior (escape) being shown by one of the opponents or when both piglets moved away from each other (Langbein and Puppe, 2004; Borberg and Hoy, 2009; Samarakone and Gonyou, 2009; Krauss and Hoy, 2011; Rhim, 2012).

Data analysis was performed using the SAS software (SAS Inst. Cary, NY, USA), with the pen serving as the experimental unit. The residual data sets were tested for normal distribution using the Univariate Procedure of SAS

Table 1. Ethogram of behavioral categories and their respective definitions

\begin{tabular}{ll}
\hline Behavior & \multicolumn{1}{c}{ Description } \\
\hline Drinking & Drinking water or manipulating the drinker with or without ingestion of water \\
Feeding & Head positioned in the feeder or chewing food displaced from the feeder \\
Chewing & Chewing (not on another pig) with head raised and turned away from the feeder \\
Inactive & Motionless and sleeping \\
Agonistic & Biting, head-thrusting, ramming, or pushing another piglet \\
Locomotion & Any movement including walking, running, scampering, and rolling \\
Pen exploration & Sniffing, touching, sucking, or chewing any object that is part of the pen \\
Belly nosing & Repeated thrusting of snout into the belly of another pig \\
Excretion & Defecating or urinating \\
Other & All other behaviors not listed above \\
\hline
\end{tabular}

Adapted from Statham et al., 2011; Rhim, 2012. 


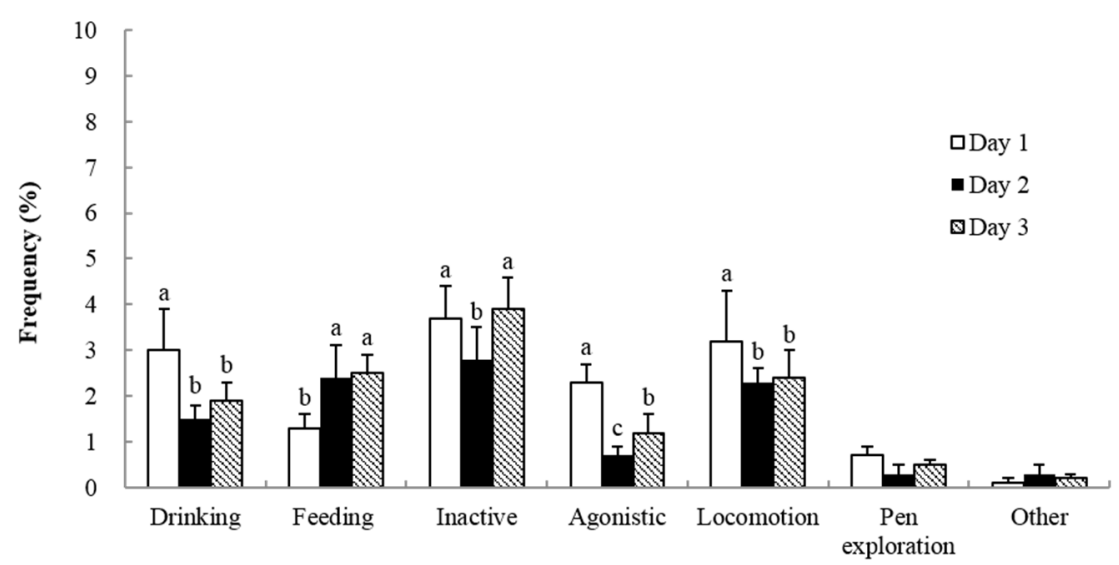

Figure 1. Square root transformed least square means ( \pm standard error) for proportion of time spent in behaviors in the control (littermates) groups of weaned piglets on days 1, 2, and 3 after mixing. Different letters indicate significant differences between mean values for a given behavior $(\mathrm{p}<0.05)$.

(Rhim et al., 2015). The data were not normally distributed and were transformed using a logarithm $\left(X^{\prime}=\log 10\right.$ $(X+0.5)+0.5)$ to achieve normal distribution (Zar, 1999). The behavioral data were analyzed by an analysis of variance (ANOVA). Tukey's post hoc tests were used to determine pairwise differences between days. Moreover, we compared variables of agonistic behavior between the control and treatment groups for each day using a multivariate analysis of variance (MANOVA). $p$ Values are presented.

\section{RESULTS}

The behaviors of the weaned piglets were significantly different among the days after mixing in the control (ANOVA, $F=11.3, \mathrm{p}<0.05)$ and treatment $(\mathrm{F}=9.8, \mathrm{p}<0.05)$ groups. There were no differences in behaviors between males and females in each groups $(\mathrm{F}=0.1 \sim 1.4, \mathrm{p}>0.2)$. However, interaction of treatment $\times$ time $\times$ sex was significantly differed $(\mathrm{F}=10.6, \mathrm{p}<0.05)$.

In the control group, drinking, agonistic, and locomotory behaviors were higher on day 1 than on days 2 and 3 . Feeding behavior was lower on day 1 than on days 2 and 3. Inactivity was higher on days 1 and 3 (Tukey's test, $\mathrm{p}<0.01)$. Pen exploration and other behaviors were not significantly different among days 1, 2, and 3 (Figure 1). Piglets had higher drinking and lower feeding behavior in day 1 . It would be caused by stress of agonistic behavior in the first day of mixing. In day 3, piglets had lower drinking and higher feeding and inactive. These changes of behavior might be related with decrease of agonistic behavior in day 3 compared to day 1 .

Drinking, inactivity, agonistic behavior, locomotion, and pen exploration were significantly different among the days after mixing in the treatment groups. Drinking, locomotion, and pen exploration were higher on day 1 than on days 2 and 3. However, agonistic behavior was lower on day 3 than on days 1 and 2 . Time spent being inactive was greater

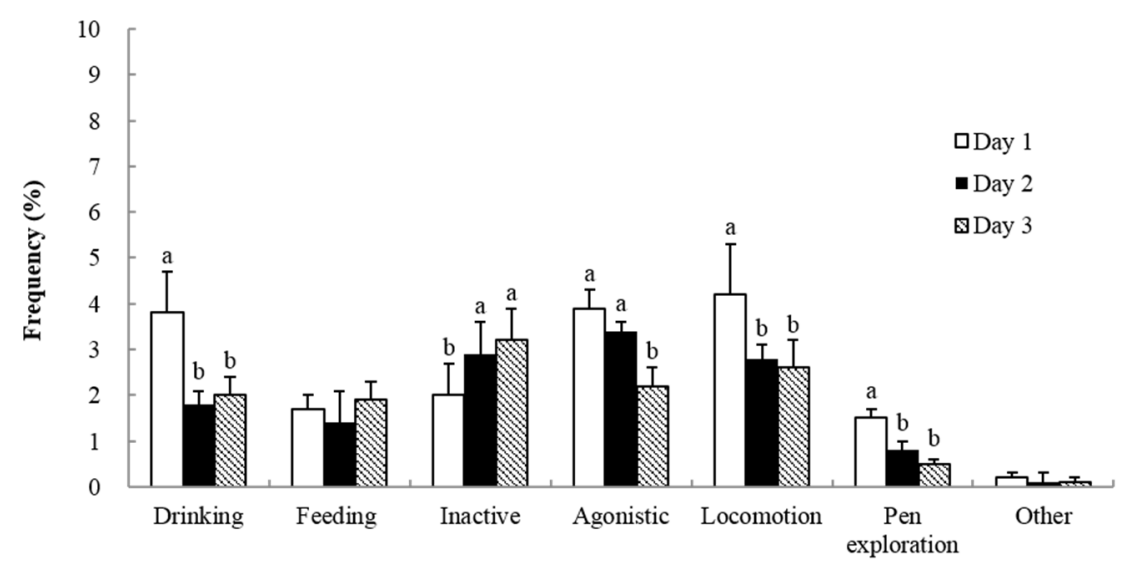

Figure 2. Square root transformed least square means ( \pm standard error) for proportion of time spent in behaviors in the treatment (foreign) groups of weaned piglets on days 1, 2, and 3 after mixing. Different letters indicate significant differences between mean values for a given behavior $(\mathrm{p}<0.05)$. 
on days 2 and 3 than on day $1(\mathrm{p}<0.05)$. Feeding and other behaviors did not differ among days 1, 2, and 3 (Figure 2).

Agonistic latency was significantly different between the control and treatment groups on day 1 (MANOVA, $\mathrm{F}=$ $6.37, \mathrm{p}<0.05)$ and $2(\mathrm{~F}=8.29, \mathrm{p}<0.05)$. Moreover, the duration of agonistic behavior was significantly higher in the treatment group than in the control group on day $1(\mathrm{~F}=$ $12.68, \mathrm{p}<0.01)$ and day $2(\mathrm{~F}=13.59, \mathrm{p}<0.01)$. There were no differences in the frequency of agonistic behavior on days 1 and $3 \quad(p>0.05)$. Agonistic frequency was significantly different between the control and treatment groups on day $2(\mathrm{~F}=8.91, \mathrm{p}<0.05)$. On day 3 , there were no significant differences in agonistic variables between the control and treatment groups. However, agonistic encounters were higher in the treatment group than in the control group on days 1 and 2 (Table 2). Piglets of treatment group displayed a higher activity (e.g. agonistic, drinking, locomotion) when compare to normal or control.

\section{DISCUSSION}

A behavioral ecology approach may complement the more traditional approaches in solving problems in swine production (Andersen et al., 2000). In this study, various behaviors were observed in weaned piglets after mixing, such as drinking, feeding, chewing, inactivity, agonistic behavior, locomotion, pen exploration, belly nosing, excretion, and other behaviors. Differences between the control and treatment groups for some behaviors, such as feeding, chewing, belly nosing, and excretion, were subtle in the first 3 days after mixing. However, some behaviors were significantly different between the groups.

This study showed that agonistic, locomotory, and drinking behaviors were higher on day 1 after mixing in both the control and treatment groups. Mixing also involves a sudden separation from the sow and a change in diet from milk to solid food. Therefore, mixing can contribute to a combination of stressors in piglets (Wiseman et al., 1998; D'Eath, 2005; Colson et al., 2006). Mixing of weaned piglets is followed by severe agonistic behavior, which can cause critical problems in animal welfare (Merlot et al.,
2004). Some studies have revealed that the amount of distress suffered by piglets at mixing is associated with the quality of the nursery facilities, diet, and management (Benson and Rollin, 2004; Parratt et al., 2006; Chaloupková et al., 2007).

The results of this study indicate that piglets from the same litter were less agonistic compared to piglets from foreign litters. In the control groups, inactive and feeding variables were higher than in the treatment groups. In contrast, piglets in treatment groups were very active (a great deal of time spent in locomotion and pen exploration) and aggressive (showing highly agonistic encounters). The piglets in the treatment groups may be more stressed than those in the control groups. In addition, agonistic behaviors among piglets decreased on days 2 and 3 compared to those observed on day 1 in the control and treatment groups. Mixing is one of the major factors that influence social structure of pigs in each pen. Mixing with littermates has distress advantages compared with mixing with foreign piglets. The problem with agonistic encounters can be reduced at weaning by using littermates to form pen groups.

This agrees with results of previous studies that found unfamiliar pigs were more aggressive towards each other than towards familiar pigs when they were mixed (Parratt et al., 2006; Li and Johnston, 2009; Li and Wang, 2011). Grouping piglets according to litter origin has been shown to be related to the degree of aggression (Colson et al., 2006). Moreover, weanling exposure to foreign piglets at early stages of life can be stressful and can affect growth rate, lead to aggression, and cause injury (D'Eath, 2005).

To conclude, agonistic behavior in weaned piglets after mixing was higher in groups of foreign piglets than in littermate groups. Moreover, agonistic encounters decreased over time after mixing. Different weaning practices certainly affect behavior of piglets in many ways. In general practice, 3 to 4 litters are grouped and penned and certainly larger group with bigger pen may also be adopted. There is little evidence to show that aggression is minimized among pigs of an optimal group size and composition. Further research is needed to determine whether piglets adopt different strategies for aggressive behavior according to

Table 2. Agonistic behavior of weaned piglets in days 1,2, and 3 after mixing between the control (Con) and treatment (Trt) groups

\begin{tabular}{|c|c|c|c|c|c|c|c|c|c|}
\hline & \multicolumn{3}{|c|}{ Day 1} & \multicolumn{3}{|c|}{ Day 2} & \multicolumn{3}{|c|}{ Day 3} \\
\hline & Con & Trt & $\mathrm{F}^{1}$ & Con & Trt & $\mathrm{F}$ & Con & Trt & $\mathrm{F}$ \\
\hline Agonistic latency (min) & 2.3 & 5.0 & & 2.0 & 5.3 & & 2.6 & 4.2 & \\
\hline Transformed data & 0.9 & 1.3 & $6.37^{*}$ & 0.8 & 1.4 & $8.29 *$ & 1.0 & 1.2 & 1.35 \\
\hline Duration of agonistic $(\mathrm{s} / \mathrm{h})$ & 139.5 & 301.4 & & 122.7 & 404.3 & & 157.1 & 256.3 & \\
\hline Transformed data & 2.1 & 2.9 & $12.68 * *$ & 2.0 & 3.1 & $13.59 * *$ & 2.3 & 2.6 & 2.45 \\
\hline Agonistic frequency (number/h) & 175.4 & 163.6 & & 38.6 & 161.4 & & 63.4 & 122.7 & \\
\hline Transformed data & 2.3 & 2.3 & 0.19 & 1.7 & 2.3 & $8.91 *$ & 1.9 & 2.1 & 1.97 \\
\hline
\end{tabular}

${ }^{1}$ Comparisons between the control and treatment groups based on a multivariate analysis of variance (MANOVA).

$* \mathrm{p}<0.05, * * \mathrm{p}<0.01$ 
group size and composition.

\section{CONFLICT OF INTEREST}

We certify that there is no conflict of interest with any financial organization regarding the material discussed in the manuscript.

\section{ACKNOWLEDGMENTS}

This study was supported by the Agriculture Science and Technology Project (Grant Number: PJ009971) of the Rural Development Administration, Republic of Korea and by the Chung-Ang University Research Scholarship Grants in 2015 .

\section{REFERENCES}

Andersen, I. L., H. Andenæs, K. E. Bøe, P. Jensen, and M. Bakken. 2000. The effects of weight asymmetry and resource distribution on aggression in groups of unacquainted pigs. Appl. Anim. Behav. Sci. 68:107-120.

Arey, D. S. and S. A. Edwards. 1998. Factors influencing aggression between sows after mixing and the consequences for welfare and production. Livest. Prod. Sci. 56:61-70.

Benson, G. J. and B. E. Rollin. 2004. The well-being of farm animals: challenges and solutions. Blackwell Publishing, Ames, IA, USA.

Borberg, C. and S. Hoy. 2009. Mixing of sows with or without the presence of a boar. Livest. Sci. 125:314-317.

Broom, D. M. 2011. Animal welfare: Concepts, study methods and indicators. Rev. Colomb. Cienc. Pecu. 24:306-321.

Chaloupková, H., G. Illmann, L. Bartoš, and M. Špinka. 2007. The effect of pre-weaning housing on the play and agonistic behaviour of domestic pigs. Appl. Anim. Behav. Sci. 103:2534.

Colson, V., P. Orgeur, V. Courboulay, S. Dantec, A. Foury, and P. Mormède. 2006. Grouping piglets by sex at weaning reduces aggressive behaviour. Appl. Anim. Behav. Sci. 97:152-172.

D'Eath, R. B. 2005. Socialising piglets before weaning improves social hierarchy formation when pigs are mixed post-weaning. Appl. Anim. Behav. Sci. 93:199-211.

Fels, M., S. Hoy, and J. Hartung. 2012. Influence of origin litter on social rank, agonistic behaviour and growth performance of piglets after weaning. Appl. Anim. Behav. Sci. 139:225-232.
Giersing, M. and A. Andersson. 1998. How does former acquaintance affect aggressive behaviour in repeatedly mixed male and female pigs? Appl. Anim. Behav. Sci. 59:297-306.

Hillman, E., F. von Hollen, B. Bunger, D. Todt, and L. Schrader. 2003. Farrowing conditions affect the reactions of piglets towards novel environment and social confrontation at weaning. Appl. Anim. Behav. Sci. 81:99-109.

Krauss, V. and S. Hoy. 2011. Dry sows in dynamic groups: An investigation of social behaviour when introducing new sows. Appl. Anim. Behav. Sci. 130:20-27.

Langbein, J. and B. Puppe. 2004. Analyzing dominance relationships by sociometric methods - a plea for a more standardized and precise approach in farm animals. Appl. Anim. Behav. Sci. 87:293-315.

Li, Y. and L. J. Johnston. 2009. Behavior and performance of pigs previously housed in large groups. J. Anim. Sci. 87:1472-1478.

Li, Y. and L. Wang. 2011. Effects of previous housing system on agonistic behaviors of growing pigs at mixing. Appl. Anim. Behav. Sci. 132:20-26.

Merlot, E., M. C. Meunier-Salaun, and A. Prunier. 2004. Behavioural, endocrine and immune consequences of mixing in weaned piglets. Appl. Anim. Behav. Sci. 85:247-257.

Parratt, C. A., K. J. Chapman, C. Turner, P. H. Jones, M. T. Mendl, and B. G. Miller. 2006. The fighting behaviour of piglets mixed before and after weaning in the presence or absence of a sow. Appl. Anim. Behav. Sci. 101:54-67.

Rhim, S. J. 2012. Effects of group size on agonistic behaviors of commercially housed growing pigs. Rev. Colomb. Cienc. Pecu. 25:353-359.

Rhim, S. J., J. S. Kim, C. K. Kim, M. G. Pang, I. K. Paik, W. S. Lee, M. B. Chang, and Y. J. Choi. 2005. Understanding and Application of animal Behavior. Life Science Publishing, Seoul, Korea.

Rhim, S. J., S. H. Son, H. S. Hwang, J. K. Lee, and J. K. Hong. 2015. Effects of mixing on the aggressive behavior of commercially housed pigs. Asian Australas. J. Anim. Sci. 28:1038-1043.

Samarakone, T. S. and H. W. Gonyou. 2009. Domestic pigs alter their social strategy in response to social group size. Appl. Anim. Behav. Sci. 121:8-15.

Varley, M. and J. Wiseman. 2001. The Weaner Pig. CABI Publishing, Oxford, UK.

Wiseman, J., M. A. Varley, and J. P. Chadwick. 1998. Progress in Pig Science. Nottingham University Press, Nottingham, UK.

Zar, J. H. 1999. Biostatistical Analysis, 4th ed. Printice-Hall Inc., Upper Saddler River, NJ, USA. 